\title{
A Randomized Phase III Trial on the Role of Esophagectomy in Complete Responders to Preoperative Chemoradiotherapy for Esophageal Squamous Cell Carcinoma (ESOPRESSO)
}

\author{
SOOK RYUN PARK ${ }^{1 *}$, DOK HYUN YOON ${ }^{1 *}$, JONG HOON KIM ${ }^{2}$, YONG-HEE KIM ${ }^{3}$, HYEONG RYUL KIM ${ }^{3}$, \\ HYUN JOO LEE ${ }^{4}$, HWOON-YONG JUNG ${ }^{5}$, GIN-HYUG LEE ${ }^{5}$, HO JUNE SONG ${ }^{5}$, DO HOON KIM ${ }^{5}$, KEE DON CHOI ${ }^{5}$, \\ JEONG HOON LEE ${ }^{5}$, JI YONG AHN ${ }^{5}$, JIN-SOOK RYU ${ }^{6}$, KYUNG-JA CHO ${ }^{7}$ and SUNG-BAE KIM ${ }^{1}$ \\ ${ }^{1}$ Department of Oncology, ${ }^{2}$ Department of Radiation Oncology, ${ }^{3}$ Department of Thoracic Surgery, \\ ${ }^{4}$ Department of Radiology, ${ }^{5}$ Department of Gastroenterology, ${ }^{6}$ Department of Nuclear Medicine, and \\ ${ }^{7}$ Department of Pathology, Asan Medical Center, University of Ulsan College of Medicine, Seoul, Republic of Korea
}

\begin{abstract}
Background/Aim: We investigated the role of esophagectomy after clinical complete response $(c C R)$ to chemoradiotherapy for esophageal squamous cell carcinoma (ESCC). Patients and Methods: Patients with resectable cT3-T4a/anyN/MO or anyT/N+/MO thoracic ESCC received two cycles of induction chemotherapy and then chemoradiotherapy (50.4 Gy/28 fractions). Patients with $c C R$ were randomized to surgery or observation. Results: Among 86 patients, 38 (44.2\%) achieved cCR after chemoradiotherapy; 37 were randomized to surgery $(n=19)$ or observation $(n=18)$. Although there were trends of better disease-free survival (DFS) toward the surgery arm in the intent-to-treat analysis (2-year DFS, $66.7 \%$ vs. $42.7 \%$; $p=0.262)$ or as-treated analysis $(66.7 \%$ vs. 50.2\%; $p=0.273)$, overall survival was not different between the two arms in the intent-to-treat $(H R=1.48 ; p=0.560)$ or astreated analysis $(H R=1.09 ; p=0.903)$. Among the 11 patients having recurrence during observation, 8 underwent surgery $(n=7)$ or endoscopic dissection $(n=1)$. Conclusion: Close observation with salvage surgery might be a reasonable option in resectable ESCC patients achieving cCR after chemoradiation.
\end{abstract}

\footnotetext{
*These Authors contributed equally to this work.

Correspondence to: Prof. Sung-Bae Kim, MD, Ph.D., Department of Oncology, Asan Medical Center, University of Ulsan College of Medicine, 88 Olympic-ro, 43-gil, Songpa-gu, Seoul, 05505, Republic of Korea. Tel: +82 230103217, Fax: +82 230106961, e-mail: sbkim3@amc.seoul.kr
}

Key Words: Esophageal squamous cell carcinoma, chemoradiotherapy, induction chemotherapy, clinical complete response, surgery, observation.
Despite recent advances in treatment, esophageal cancer is still one of the deadliest malignancies (1). Even patients with potentially resectable disease have a poor prognosis with 5-year overall survival (OS) rates of $15-20 \%$ with surgery alone, which underscores the value of multidisciplinary treatment approaches $(2,3)$. Currently, neoadjuvant chemoradiation followed by surgery is the preferred treatment for potentially resectable stage II-III thoracic esophageal cancer (EC) based on the survival benefits compared to surgery alone (4-7). However, it is unclear whether surgery is required in patients who have received chemoradiation, given that radical esophagectomy is associated with significant morbidity and mortality.

In a randomized phase III study comparing induction chemotherapy followed by chemoradiotherapy with or without surgery for locally advanced esophageal squamous cell carcinoma (ESCC), the addition of surgery resulted in better locoregional control but did not translate to survival benefits due to a higher risk of treatment-related death (8). Patients with tumor response to induction chemotherapy had a high 3-year survival rate, regardless of the treatment group (8). Another phase III study (FFCD 9102) compared continuation of chemoradiotherapy to surgery in patients responding to chemoradiation for advanced $\mathrm{EC}$, which also did not demonstrate survival benefits of the addition of surgery (9). A recent Cochrane analysis also suggested that chemoradiotherapy appears to be at least equivalent to surgery in terms of short- and long-term survival in ESCC patients who are fit for surgery and are responsive to induction chemoradiotherapy (10). Although chemoradiation followed by surgery remains the preferred treatment approach for resectable EC in medically fit patients, the role of surgery in long-term outcomes needs to be elucidated, particularly for patients responding to chemoradiation. Therefore, in this single-center, open-label, randomized, 
phase III trial, we investigated the role of esophagectomy in patients who achieved a clinical complete response (cCR) after chemoradiation for locally advanced ESCC.

\section{Patients and Methods}

Eligibility criteria. The key eligibility criteria were: histologically confirmed, resectable cT3-T4a/anyN/M0 or anyT/N+/M0 (the 7th edition of the AJCC staging system) thoracic ESCC, age 20-75 years, Eastern Cooperative Oncology Group performance status 0-2, adequate major organs function, and no history of other cancers within 5 years. Pre-treatment staging work-up included esophagogastroduodenoscopy with biopsy, thoracic/abdominal/pelvic computed tomography (CT), endoscopic ultrasonography, bone scan, ${ }^{18} \mathrm{~F}$ fluorodeoxyglucose (FDG)-positron emission tomography (PET), and bronchoscopy when needed. All patients gave written informed consent before study enrolment. The study was approved by the institutional review board of Asan Medical Center, Korea (IRB approval number: 2012-0817), and conducted in accordance with the principles of the Declaration of Helsinki. The trial was registered at ClinicalTrials.gov (NCT01740375).

Treatment and evaluation. Patients received two cycles of induction chemotherapy (capecitabine $1,000 \mathrm{mg} / \mathrm{m}^{2}$ twice daily on D1-14 and cisplatin $60 \mathrm{mg} / \mathrm{m}^{2}$ intravenously on D1 every 3 weeks) and proceeded to chemoradiation if they had a response or stable disease (SD) on PET after induction chemotherapy, according to European Organization for Research and Treatment of Cancer criteria (11). Radiotherapy was delivered once a day to a total dose of 50.4 Gy in 28 fractions of $1.8 \mathrm{~Gy}$ with a 15 -MV linear accelerator. The clinical target volume included the primary tumor with a $5-\mathrm{cm}$ cranio-caudal margin and 2-cm lateral margin and regional lymph nodes (LNs). Supraclavicular LNs were routinely encompassed in upper thoracic EC and celiac LNs in distal or middle thoracic EC. During radiotherapy, concurrent chemotherapy was administered with capecitabine $800 \mathrm{mg} / \mathrm{m}^{2}$ twice daily for 5 days/week and cisplatin $30 \mathrm{mg} / \mathrm{m}^{2}$ weekly. Adverse events were assessed using the Common Terminology Criteria for Adverse Events v4.03.

Four weeks after completing chemoradiation, patients were reevaluated with endoscopy with biopsy, chest CT, and PET-CT. cCR was defined as no radiographic or metabolic evidence of disease without residual tumor on endoscopy with biopsy. Complete metabolic response was complete resolution of FDG uptake within all lesions, making them indistinguishable from surrounding tissue. Otherwise, the response was assessed according to Response Evaluation Criteria in Solid Tumors (RECIST) v1.1 (12). Only patients who achieved a cCR after chemoradiation were randomized (1:1) through the block randomization method to surgery or observation, stratified by the presence of $\mathrm{LN}$ metastasis.

Surgical resection via an abdominal-right thoracic approach (Ivor-Lewis) or right thoracic-abdominal-cervical approach (McKeown) with two-field LN dissection was preferentially performed within 6-8 weeks and not exceeding 12 weeks after completing chemoradiation. The proximal and distal margins had to be at least $6-8 \mathrm{~cm}$ from the gross tumor. The pathologic response was evaluated according to the percentage of vital tumor tissue in relation to the macroscopically identifiable tumor bed: grade 1 , $>50 \%$ of residual tumor cells; grade $2,10-50 \%$; grade $3,<10 \%$; and grade 4, no viable tumor (13). Pathologic CR (pCR) was defined by the absence of viable cancer cells in the esophagus and LNs.

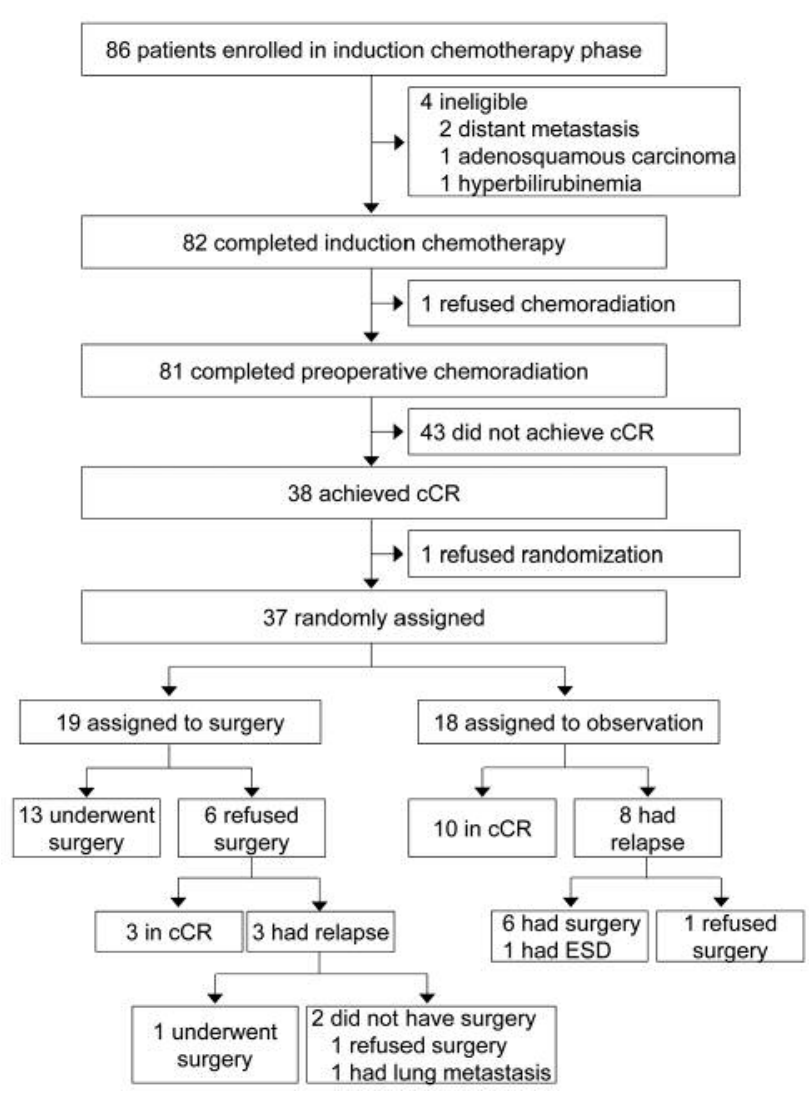

Figure 1. CONSORT diagram. cCR: Clinical complete response; ESD; endoscopic submucosal dissection.

Follow-up after randomization included OPD visits at 3-month intervals for the first 2 years and then every 6 months from 3-5 years with $\mathrm{CT}$ and endoscopy every 6 months.

Statistical analysis. The primary endpoint was disease-free survival (DFS), which was defined as the time between randomization and progression or death from any cause. The secondary endpoints included progression-free survival (PFS; the time between initiation of chemotherapy and progression or death), time to progression (TTP; the time between initiation of chemotherapy and progression), OS (the time between initiation of chemotherapy and death), the failure pattern, the pCR rate, treatment outcomes according to metabolic or clinical response, safety, and quality of life. For patients who had cCR and/or R0 or R1 resection, progression was defined as the first clinical evidence of relapse. Patients with R1 resection were regarded as having progressed only when there was clinical or radiological evidence of disease progression before surgery. For patients not macroscopically free of disease after surgery or not undergoing surgery due to progression, progression was defined as occurring at the time of surgery or at the time of clinical evaluation showing unresectable disease.

Sample size calculations showed that 194 patients (78 DFS events required) were needed to detect an increase in the 2-year DFS rate from $50 \%$ to $70 \%$ (hazard ratio $[\mathrm{HR}]=0.514$ ) among 
Table I. Baseline characteristics.

\begin{tabular}{|c|c|c|c|c|}
\hline & \multirow[t]{2}{*}{ Entire population $(n=82)$} & \multicolumn{2}{|c|}{ Randomized population } & \multirow[b]{2}{*}{$p$-Value } \\
\hline & & Surgery arm $(n=19)$ & Observation arm $(\mathrm{n}=18)$ & \\
\hline Age (years) & $60(55-67)$ & $62(56-69)$ & $61(55-67)$ & 0.819 \\
\hline Gender & & & & 0.230 \\
\hline Male & $79(96.3 \%)$ & $19(100 \%)$ & $16(88.9 \%)$ & \\
\hline Female & $3(3.7 \%)$ & $0(0 \%)$ & $2(11.1 \%)$ & \\
\hline ECOG performance status & & & & 0.582 \\
\hline 0 & $48(58.5 \%)$ & $11(57.9 \%)$ & $12(66.7 \%)$ & \\
\hline 1 & $34(41.5 \%)$ & $8(42.1 \%)$ & $6(33.3 \%)$ & \\
\hline Tumor location & & & & 0.788 \\
\hline Upper third & $7(8.5 \%)$ & $0(0 \%)$ & $1(5.6 \%)$ & \\
\hline Middle third & $26(31.7 \%)$ & $5(26.3 \%)$ & $6(33.3 \%)$ & \\
\hline Lower third & $46(56.1 \%)$ & $13(68.4 \%)$ & $10(55.6 \%)$ & \\
\hline Multifocal/diffuse spreading & $3(3.7 \%)$ & $1(5.3 \%)$ & $1(5.6 \%)$ & \\
\hline Histological grade & & & & 1.000 \\
\hline Well differentiated & $13(15.9 \%)$ & $2(10.5 \%)$ & $3(16.7 \%)$ & \\
\hline Moderately differentiated & $61(74.4 \%)$ & $15(78.9 \%)$ & $14(77.8 \%)$ & \\
\hline Poorly differentiated & $7(8.5 \%)$ & $2(10.5 \%)$ & $1(5.6 \%)$ & \\
\hline Unknown & $1(1.2 \%)$ & $0(0 \%)$ & $0(0 \%)$ & \\
\hline Clinical T stage & & & & 0.128 \\
\hline $\mathrm{T} 1$ & $8(9.8 \%)$ & $1(5.3 \%)$ & $6(33.3 \%)$ & \\
\hline $\mathrm{T} 2$ & $15(18.3 \%)$ & $2(10.5 \%)$ & $2(11.1 \%)$ & \\
\hline $\mathrm{T} 3$ & $55(67.1 \%)$ & $15(78.9 \%)$ & $10(55.6 \%)$ & \\
\hline $\mathrm{T} 4$ & $4(4.9 \%)$ & $1(5.3 \%)$ & $0(0 \%)$ & \\
\hline Clinical N stage & & & & 0.807 \\
\hline No & $16(19.5 \%)$ & $4(21.1 \%)$ & $5(27.8 \%)$ & \\
\hline N1 & $42(51.2 \%)$ & $10(52.6 \%)$ & $11(61.1 \%)$ & \\
\hline $\mathrm{N} 2$ & $20(24.4 \%)$ & $4(21.1 \%)$ & $2(11.1 \%)$ & \\
\hline N3 & $4(4.9 \%)$ & $1(5.3 \%)$ & $0(0 \%)$ & \\
\hline Clinical TNM stage & & & & $0.014 *$ \\
\hline IIA & $8(9.8 \%)$ & $2(10.5 \%)$ & $3(16.7 \%)$ & \\
\hline IIB & $21(25.6 \%)$ & $3(15.8 \%)$ & $9(50.0 \%)$ & \\
\hline IIIA & $33(40.2 \%)$ & $9(47.4 \%)$ & $5(27.8 \%)$ & \\
\hline IIIB & $13(15.9 \%)$ & $3(15.8 \%)$ & $1(5.6 \%)$ & \\
\hline IIIC & $7(8.5 \%)$ & $2(10.5 \%)$ & $0(0 \%)$ & \\
\hline
\end{tabular}

Data are median (interquartile range) or number $(\%) .{ }^{*} p$-value for stage 2 vs. 3. ECOG: Eastern Cooperative Oncology Group.

patients undergoing surgery with $80 \%$ power and a two-sided $\alpha$ of 0.05 . Assuming a $40 \%$ rate of cCR, 486 patients were planned. Time to event endpoints were characterized by the Kaplan-Meier method, and treatment groups were compared using the log-rank test and Cox proportional hazard regression models (unadjusted). We compared variables with the $\chi^{2}$ test, Fisher exact test, or a nonparametric Wilcoxon test, depending on their type and distribution. All statistical tests were two-sided, and we considered $p<0.05$ significant.

\section{Results}

Patient characteristics. Between November 2012 and March 2016, 86 patients (17.7\% of the target number) were enrolled. The accrual was slower than expected, causing early study closure. Among the 82 eligible patients, 38 patients (44.2\%) achieved a cCR after chemoradiation; of these, 37 were randomized to surgery $(n=19)$ or observation $(n=18)$ (Figure 1). Patient characteristics were well balanced between the treatment arms except for clinical TNM stages (stage $>2,73.7 \%$ in the surgery arm $v s .33 .3 \%$ in the observation arm; $p=0.014$ ) (Table I).

Induction chemotherapy and chemoradiation. All eligible 82 patients completed induction chemotherapy, and postchemotherapy PET showed a CR in 7 patients $(8.5 \%)$, partial response (PR) in $62(75.6 \%)$, and $\mathrm{SD}$ in $12(14.6 \%)$; one patient $(1.2 \%)$ refused PET. Eighty-one patients proceeded to chemoradiotherapy; of these, $78(96.3 \%)$ received 50.4 Gy of radiotherapy, 2 received $46.0 \mathrm{~Gy}$, and 1 received $46.8 \mathrm{~Gy}$. The post-chemoradiation metabolic response evaluation showed a $\mathrm{CR}$ in 38 patients (46.3\%), PR in 35 (43.2\%), SD in 1 (1.2\%), and progressive disease (PD) in $6(7.3 \%)$; one patient was not 
evaluable. According to RECIST, post-chemoradiation evaluation showed a CR in 39 patients $(47.6 \%), P R$ in 6 $(7.3 \%), \mathrm{SD}$ or NonCR/NonPD in $31(37.8 \%)$, and PD in 5 $(6.1 \%)$. Adverse events during induction chemotherapy and chemoradiation are shown in Table II.

Compliance with the allocated arm. The compliance rates significantly differed between the allocated arms $(68.4 \%$ in the surgery arm and $100 \%$ in the observation arm; $p=0.020)$. In the surgery arm, only 13 patients (68.4\%) underwent surgery; the remaining six declined surgery after chemoradiotherapy and were followed without any treatment until disease progression. In the observation arm, all patients were followed without any treatment until disease progression (Figure 1).

Surgery results. In the surgery arm, 12 of 13 patients (92.3\%) undergoing surgery had R0 resection, whereas one patient $(7.7 \%)$ had $\mathrm{R} 1$ resection. In the observation arm, eight patients experienced recurrence, all locoregional, during observation. Of these, one patient refused surgery, one patient received curative endoscopic dissection, and six patients underwent surgery: $\mathrm{R} 0$ resection in three patients ( 3 of $6,50.0 \%$ ) and $\mathrm{R} 1$ resection in three patients (3 of 6 , $50.0 \%)$. In the intent-to-treat analysis, the surgery arm had a higher $\mathrm{R} 0$ resection rate $(92.3 \%$ versus $50.0 \% ; p=0.071)$, lower pathologic T $(p=0.008)$ and TNM $(p=0.002)$ stages, and higher degree of pathologic regression $(p<0.0001)$ than the observation arm (Table III). In the as-treated analysis, the surgery arm also had a significantly higher $\mathrm{R} 0$ resection rate $(92.3 \%$ versus $42.9 \% ; p=0.031)$ and pathologic regression grade $(p<0.0001)$ and lower pathologic $\mathrm{T}$ $(p=0.003)$ and TNM $(p=0.0005)$ stages than patients who underwent salvage surgery in the observation arm (Table III). Although there was no 30-day mortality after surgery in both arms, one patient in the surgery arm died of recurrent pneumonia 74 days after surgery which was considered surgery-related death.

Survival. Among the 82 eligible patients, patients who achieved a cCR had a better TTP [31.9 months (95\% CI=not estimated (NE)) vs. 16.4 months (95\%CI=NE); $p=0.116]$, PFS $[31.9$ months $\quad(95 \% \mathrm{CI}=\mathrm{NE}) \quad v s . \quad 11.6$ months (95\% CI=4.4-18.8); $p=0.041$ ], and OS [not reached $v s .21 .7$ months $(95 \% \mathrm{CI}=6.5-36.9) ; p=0.002]$ than those who did not. For the 37 randomized patients, with a median follow-up of 29.9 months (IQR=13.9-36.3), the median OS and TTP were not reached, the median PFS was 31.9 months (95\% CI=NE), and the median DFS was 27.7 months $(95 \% \mathrm{CI}=\mathrm{NE})$. In the intent-to-treat analysis, there were no significant differences in DFS, PFS, TTP, and OS between the two arms, although the surgery arm tended to have better DFS, PFS, and TTP than the observation arm (Figure 2). The median DFS was
Table II. Adverse events during induction chemotherapy and chemoradiotherapy.

\begin{tabular}{|c|c|c|c|c|}
\hline \multirow[b]{2}{*}{ Adverse events* } & \multicolumn{2}{|c|}{$\begin{array}{c}\text { Induction } \\
\text { chemotherapy } \\
(\mathrm{n}=82)\end{array}$} & \multicolumn{2}{|c|}{$\begin{array}{l}\text { Chemo- } \\
\text { radiotherapy } \\
\qquad(\mathrm{n}=81)\end{array}$} \\
\hline & Grade $1 / 2$ & Grade 3/4 & Grade $1 / 2$ & Grade $3 / 4$ \\
\hline \multicolumn{5}{|l|}{ Hematologic } \\
\hline Leukopenia & $23(28.0)$ & $1(1.2)$ & $44(54.3)$ & $30(37.0)$ \\
\hline Neutropenia & $44(53.7)$ & $3(3.7)$ & $51(63.0)$ & $24(29.6)$ \\
\hline Anemia & $14(17.1)$ & $0(0)$ & $45(55.6)$ & $3(3.7)$ \\
\hline Thrombocytopenia & $28(34.1)$ & $0(0)$ & $44(54.3)$ & $30(37.0)$ \\
\hline \multicolumn{5}{|l|}{ Non-hematologic } \\
\hline Abdominal pain & $10(12.2)$ & $1(1.2)$ & $14(17.3)$ & $0(0)$ \\
\hline Odynophagia & $18(22.0)$ & $0(0)$ & $40(49.4)$ & $1(1.2)$ \\
\hline Dysphagia & $14(17.1)$ & $1(1.2)$ & $29(35.8)$ & $1(1.2)$ \\
\hline Esophagitis & $0(0)$ & $0(0)$ & $26(32.1)$ & $0(0)$ \\
\hline Dyspepsia & $4(4.9)$ & $0(0)$ & $9(11.1)$ & $0(0)$ \\
\hline Anorexia & $8(9.8)$ & $0(0)$ & $40(49.4)$ & $0(0)$ \\
\hline Nausea & $22(26.8)$ & $1(1.2)$ & $33(40.7)$ & $0(0)$ \\
\hline Vomiting & $2(2.4)$ & $4(4.9)$ & $12(14.8)$ & $1(1.2)$ \\
\hline Constipation & $13(15.9)$ & $0(0)$ & $15(18.5)$ & $0(0)$ \\
\hline Fatigue & $39(47.6)$ & $0(0)$ & $53(65.4)$ & $0(0)$ \\
\hline Dizziness & $16(19.5)$ & $0(0)$ & $35(43.2)$ & $0(0)$ \\
\hline Hiccup & $18(22.0)$ & $0(0)$ & $5(6.2)$ & $0(0)$ \\
\hline Hand-foot syndrome & $10(12.2)$ & $0(0)$ & $20(24.7)$ & $0(0)$ \\
\hline Skin hyperpigmentation & n 12 (14.6) & $0(0)$ & $20(24.7)$ & $0(0)$ \\
\hline Cough & $3(3.7)$ & $0(0)$ & $10(12.3)$ & $0(0)$ \\
\hline Sputum & $0(0)$ & $0(0)$ & $9(11.1)$ & $0(0)$ \\
\hline Hyperbilirubinemia & $3(3.7)$ & $0(0)$ & $22(27.2)$ & $0(0)$ \\
\hline
\end{tabular}

Data are numbers of patients $(\%)$. ${ }^{*}$ Reported in $\geq 10 \%$ of patients.

21.7 months $(95 \% \mathrm{CI}=0-45.9)$ in the observation arm, whereas it was not reached in the surgery arm $(p=0.262)$ (Figure 2a). The 2-year DFS rate was 66.7\% [95\%CI $=44.9$ $88.5 \%]$ in the surgery arm $v s .42 .7 \%(95 \% \mathrm{CI}=17.0-68.4)$ in the observation arm $(\mathrm{HR}=1.75 ; 95 \% \mathrm{CI}=0.65-4.72)$. The median PFS was not reached in the surgery arm and was 25.6 months $(95 \% \mathrm{CI}=2.4-48.8)$ in the observation arm $(\mathrm{HR}=1.71 ; 95 \% \mathrm{CI}=0.63-4.61 ; p=0.282)$ (Figure $2 \mathrm{~b})$. The median TTP was not reached in the surgery arm and was 25.6 months $(95 \% \mathrm{CI}=2.7-48.5)$ in the observation arm $(\mathrm{HR}=1.83 ; 95 \% \mathrm{CI}=0.63-5.30 ; p=0.257)$ (Figure $2 \mathrm{c})$. The median OS was not reached in either arm $(\mathrm{HR}=1.48$; 95\% CI $=0.40-5.51 ; p=0.560$ ) (Figure 2d).

In the as-treated analysis, there were similar trends to the intent-to-treat analysis (Figure 2e-h). Although the surgery arm tended to have better DFS $(\mathrm{HR}=1.87 ; 95 \% \mathrm{CI}=0.60$ 5.82), PFS $(\mathrm{HR}=1.81 ; 95 \% \mathrm{CI}=0.58-5.63 ; p=0.300)$, and TTP $(\mathrm{HR}=2.25 ; 95 \% \mathrm{CI}=0.62-8.10 ; p=0.203)$ than the observation arm, OS was not different between the two arms.

In the intent-to-treat analysis, the recurrence rate was $31.6 \%$ (6 of 19) in the surgery arm and $44.4 \%$ (8 of 18) in the 
Table III. Surgical and pathologic details.

\begin{tabular}{|c|c|c|c|c|c|c|c|}
\hline & \multirow{2}{*}{$\begin{array}{c}\text { Entire } \\
\text { population } \\
(\mathrm{n}=82)\end{array}$} & \multicolumn{3}{|c|}{ Intent-to-treat analysis } & \multicolumn{3}{|c|}{ As-treated analysis } \\
\hline & & Surgery $(n=19)$ & Observation $(\mathrm{n}=18)$ & $p$-Value & Surgery $(n=13)$ & Observation $(n=24)$ & $p$-Value \\
\hline \multicolumn{8}{|l|}{ Surgery* } \\
\hline Yes & $51(62.2 \%)$ & $13(68.4 \%)$ & $6(33.3 \%)$ & & $13(100 \%)$ & $7(29.2 \%)$ & \\
\hline Extent of surgery** & & & & 0.071 & & & 0.031 \\
\hline R0 & $41(80.4 \%)$ & $12(92.3 \%)$ & $3(50.0 \%)$ & & $12(92.3 \%)$ & $3(42.9 \%)$ & \\
\hline $\mathrm{R} 1$ & $6(11.8 \%)$ & $1(7.7 \%)$ & $3(50.0 \%)$ & & $1(7.7 \%)$ & $4(57.1 \%)$ & \\
\hline $\mathrm{R} 2$ & $3(5.9 \%)$ & $0(0 \%)$ & $0(0 \%)$ & & $0(0 \%)$ & $0(0 \%)$ & \\
\hline Open \& Closure & $1(2.0 \%)$ & $0(0 \%)$ & $0(0 \%)$ & & $0(0 \%)$ & $0(0 \%)$ & \\
\hline Types of surgery** & & & & 1.000 & & & 1.000 \\
\hline Ivor-Lewis operation & $29(56.9 \%)$ & $9(69.2 \%)$ & $4(66.7 \%)$ & & $9(69.2 \%)$ & $5(71.4 \%)$ & \\
\hline McKeown operation & $20(39.2 \%)$ & $3(23.1 \%)$ & $2(33.3 \%)$ & & $3(23.1 \%)$ & $2(28.6 \%)$ & \\
\hline Others & $2(3.9 \%)$ & $1(7.7 \%)$ & $0(0 \%)$ & & $1(7.7 \%)$ & $0(0 \%)$ & \\
\hline Postoperative hospital stay (days)** & $15(13-21)$ & $14(14-18)$ & $15(12-27)$ & 0.894 & $14(14-18)$ & $15(13-18)$ & 1.000 \\
\hline $\begin{array}{l}\text { Postoperative death within } \\
30 \text { days after surgery** }\end{array}$ & $1(2.2 \%)$ & $0(0 \%)$ & $0(0 \%)$ & - & $0(0 \%)$ & $0(0 \%)$ & - \\
\hline \multicolumn{8}{|l|}{ Postoperative complications** } \\
\hline Vocal cord palsy & $19(37.3 \%)$ & $3(23.1 \%)$ & $4(66.7 \%)$ & 0.129 & $3(23.1 \%)$ & $4(57.1 \%)$ & 0.174 \\
\hline Pneumonia & $10(19.6 \%)$ & $2(15.4 \%)$ & $1(16.7 \%)$ & 1.000 & $2(15.4 \%)$ & $1(14.3 \%)$ & 1.000 \\
\hline Cardiac arrhythmia & $4(7.8 \%)$ & $2(15.4 \%)$ & $0(0 \%)$ & 1.000 & $2(15.4 \%)$ & $0(0 \%)$ & 0.521 \\
\hline Wound infection & $3(5.9 \%)$ & $0(0 \%)$ & $1(16.7 \%)$ & 0.316 & $0(0 \%)$ & $1(14.3 \%)$ & 0.350 \\
\hline Chylothorax & $2(3.9 \%)$ & $0(0 \%)$ & $1(16.7 \%)$ & 0.316 & $0(0 \%)$ & $1(14.3 \%)$ & 0.350 \\
\hline Anastomosis site leakage & $5(9.8 \%)$ & $0(0 \%)$ & $0(0 \%)$ & - & $0(0 \%)$ & $0(0 \%)$ & - \\
\hline Mediastinitis & $3(5.9 \%)$ & $0(0 \%)$ & $0(0 \%)$ & - & $0(0 \%)$ & $0(0 \%)$ & - \\
\hline Bronchial fistula & $1(2.0 \%)$ & $0(0 \%)$ & $0(0 \%)$ & - & $0(0 \%)$ & $0(0 \%)$ & - \\
\hline Pathologic T stage*** & & & & 0.008 & & & 0.003 \\
\hline T0 & $17(34.0 \%)$ & $9(69.2 \%)$ & $0(0 \%)$ & & $9(69.2 \%)$ & $0(0 \%)$ & \\
\hline Tis & $2(4.0 \%)$ & $1(7.7 \%)$ & $0(0 \%)$ & & $1(7.7 \%)$ & $0(0 \%)$ & \\
\hline $\mathrm{T} 1$ & $6(12.0 \%)$ & $0(0 \%)$ & $1(16.7 \%)$ & & $0(0 \%)$ & $1(14.3 \%)$ & \\
\hline $\mathrm{T} 2$ & $6(12.0 \%)$ & $1(7.7 \%)$ & $0(0 \%)$ & & $1(7.7 \%)$ & $0(0 \%)$ & \\
\hline $\mathrm{T} 3$ & $13(26.0 \%)$ & $2(15.4 \%)$ & $3(50.0 \%)$ & & $2(15.4 \%)$ & $4(57.1 \%)$ & \\
\hline $\mathrm{T} 4 \mathrm{a}$ & $2(4.0 \%)$ & $0(0 \%)$ & $1(16.7 \%)$ & & $0(0 \%)$ & $1(14.3 \%)$ & \\
\hline $\mathrm{T} 4 \mathrm{~b}$ & $4(8.0 \%)$ & $0(0 \%)$ & $1(16.7 \%)$ & & $0(0 \%)$ & $1(14.3 \%)$ & \\
\hline Pathologic N stage*** & & & & 0.148 & & & 0.220 \\
\hline N0 & $27(54.0 \%)$ & $9(69.2 \%)$ & $2(33.3 \%)$ & & $9(69.2 \%)$ & $3(42.9 \%)$ & \\
\hline N1 & $15(30.0 \%)$ & $4(30.8 \%)$ & $2(33.3 \%)$ & & $4(30.8 \%)$ & $2(28.6 \%)$ & \\
\hline $\mathrm{N} 2$ & $7(14.0 \%)$ & $0(0 \%)$ & $1(16.7 \%)$ & & $0(0 \%)$ & $1(14.3 \%)$ & \\
\hline N3 & $1(2.0 \%)$ & $0(0 \%)$ & $1(16.7 \%)$ & & $0(0 \%)$ & $1(14.3 \%)$ & \\
\hline Pathologic TNM stage*** & & & & 0.002 & & & 0.0005 \\
\hline $\mathrm{pCR}$ & $15(30.0 \%)$ & $8(61.5 \%)$ & $0(0 \%)$ & & $8(61.5 \%)$ & $0(0 \%)$ & \\
\hline 0 & $2(4.0 \%)$ & $1(7.7 \%)$ & $0(0 \%)$ & & $1(7.7 \%)$ & $0(0 \%)$ & \\
\hline IA & $0(0 \%)$ & $0(0 \%)$ & $0(0 \%)$ & & $0(0 \%)$ & $0(0 \%)$ & \\
\hline IB & $3(6.0 \%)$ & $0(0 \%)$ & $1(16.7 \%)$ & & $0(0 \%)$ & $1(14.3 \%)$ & \\
\hline IIA & $4(8.0 \%)$ & $0(0 \%)$ & $1(16.7 \%)$ & & $0(0 \%)$ & $2(28.6 \%)$ & \\
\hline IIB & $10(20.0 \%)$ & $1(7.7 \%)$ & $0(0 \%)$ & & $1(7.7 \%)$ & $0(0 \%)$ & \\
\hline IIIA & $4(8.0 \%)$ & $2(15.4 \%)$ & $0(0 \%)$ & & $2(15.4 \%)$ & $0(0 \%)$ & \\
\hline IIIB & $3(6.0 \%)$ & $0(0 \%)$ & $1(16.7 \%)$ & & $0(0 \%)$ & $1(14.3 \%)$ & \\
\hline IIIC & $5(10.0 \%)$ & $0(0 \%)$ & $3(50.0 \%)$ & & $0(0 \%)$ & $3(42.9 \%)$ & \\
\hline IV & $2(4.0 \%)$ & $0(0 \%)$ & $0(0 \%)$ & & $0(0 \%)$ & $0(0 \%)$ & \\
\hline Other (T0N1M0) & $2(4.0 \%)$ & $1(7.7 \%)$ & $0(0 \%)$ & & $1(7.7 \%)$ & $0(0 \%)$ & \\
\hline Tumor regression grade $* * *$ & & & & $<0.0001$ & & & $<0.0001$ \\
\hline Grade 1 & $15(30.0 \%)$ & $0(0 \%)$ & $6(100 \%)$ & & $0(0 \%)$ & $7(100 \%)$ & \\
\hline Grade 2 & $7(14.0 \%)$ & $1(7.7 \%)$ & $0(0 \%)$ & & $1(7.7 \%)$ & $0(0 \%)$ & \\
\hline Grade 3 & $10(20.0 \%)$ & $3(23.1 \%)$ & $0(0 \%)$ & & $3(23.1 \%)$ & $0(0 \%)$ & \\
\hline Grade 4 & $18(36.0 \%)$ & $9(69.2 \%)$ & $0(0 \%)$ & & $9(69.2 \%)$ & $0(0 \%)$ & \\
\hline
\end{tabular}

Data are median (interquartile range) or number (\%). *Immediate surgery in the surgery arm and delayed surgery at recurrence in the observation arm; **Among patients who underwent surgery; ***Among patients who underwent esophagectomy. pCR: Pathologic complete response. 


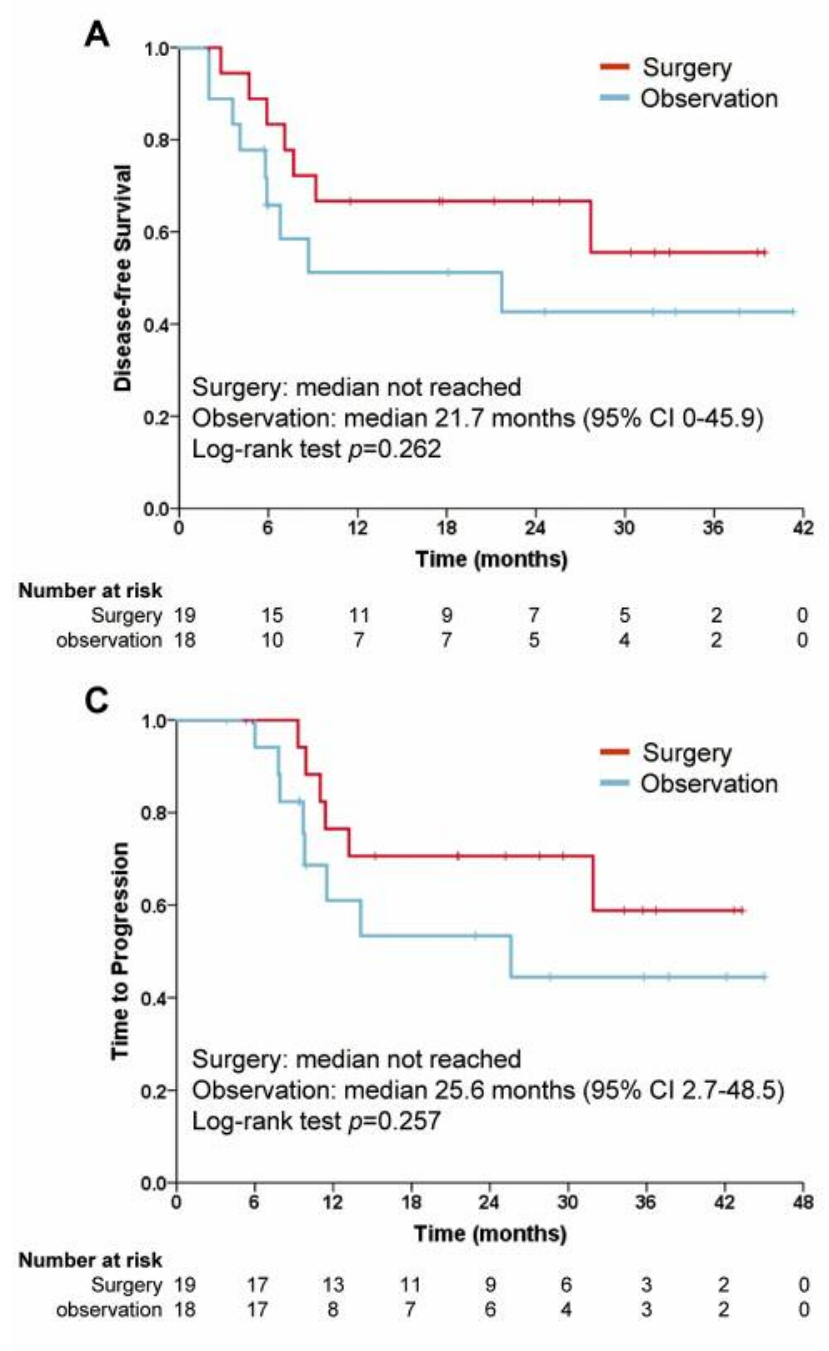

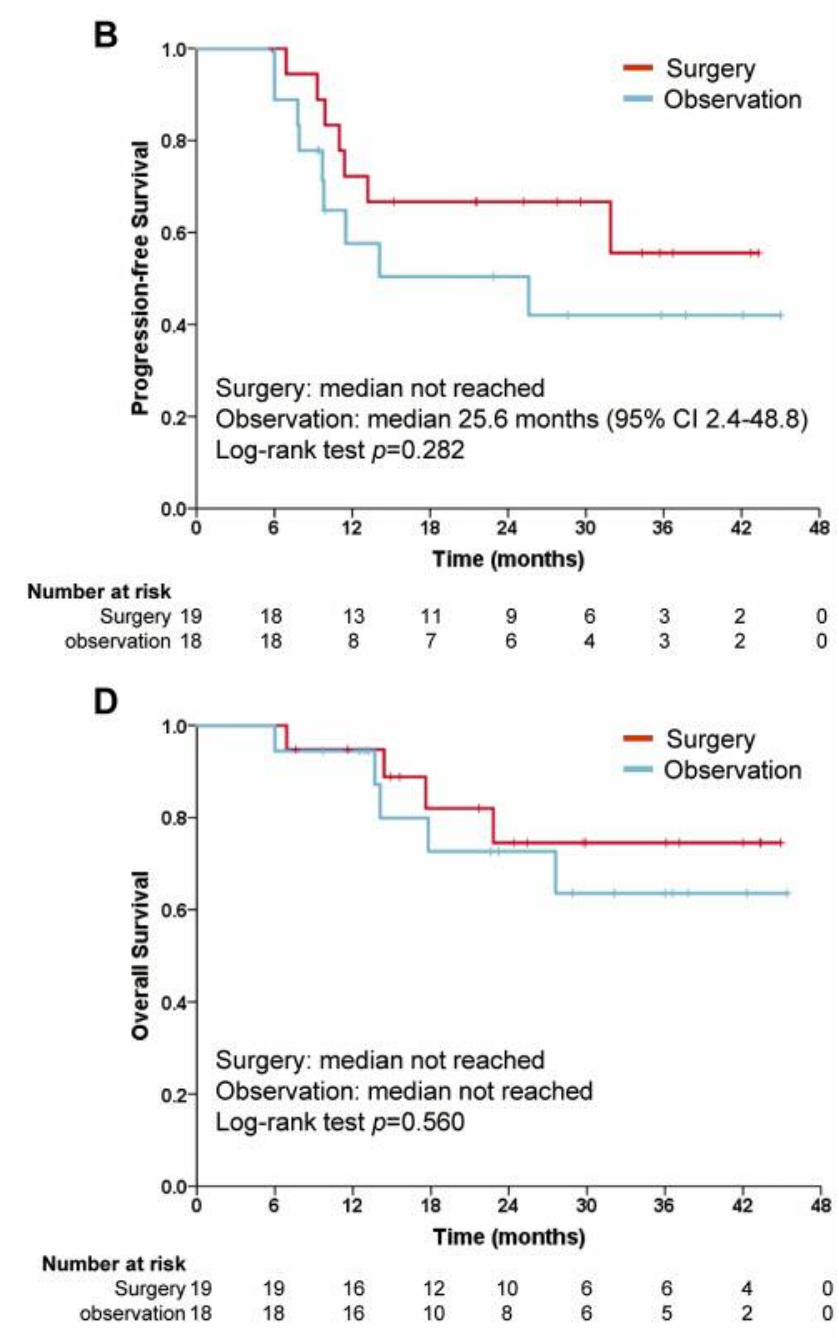

Figure 2. Continued observation arm $(p=0.420)$. The observation arm was more likely to have locoregional-only relapse at the first recurrence than the surgery arm (44.4\% vs. $15.8 \% ; p=0.056)$ (Table IV). In the as-treated analysis, the recurrence rate was $23.1 \%$ (3 of 13 ) in the surgery arm and $45.8 \%$ (11 of 24$)$ in the observation arm $(p=0.288)$. All 10 locoregional-only recurrences in the observation arm were considered resectable; eight patients underwent surgery $(\mathrm{n}=7)$ or endoscopic submucosal dissection $(n=1)$, whereas two patients refused surgery. In those patients who had local therapy for locoregional recurrence during observation, the median OS was 27.6 months $(95 \% \mathrm{CI}=7.5-$ 47.7). In the patients who had recurrence during observation, the median time to recurrence after randomization was 5.9 months $(95 \% \mathrm{CI}=4.6-7.2)$.

In the entire populations, when TTP, PFS, and OS were analyzed according to the metabolic response after induction chemotherapy and chemoradiation (Figure 3), there were significant associations between treatment outcomes and metabolic response after chemoradiation $(p<0.0001)$, whereas metabolic response after induction chemotherapy was associated with non-significant trends toward better outcomes.

\section{Discussion}

Our results revealed that surgery did not significantly prolong survival compared to observation in ESCC patients who achieved a cCR after induction chemotherapy and chemoradiation. Although DFS, PFS, and TTP tended to be better in the surgery arm than in the observation arm, the differences were not statistically significant. In particular, OS was similar between the two arms in both the intent-to-treat and as-treated analyses. The recurrence rate was numerically higher in the observation arm than in the surgery arm $[44.4 \%$ vs. $31.6 \%$ in the intent-to treat analysis $(p=0.420) ; 45.8 \%$ vs. 

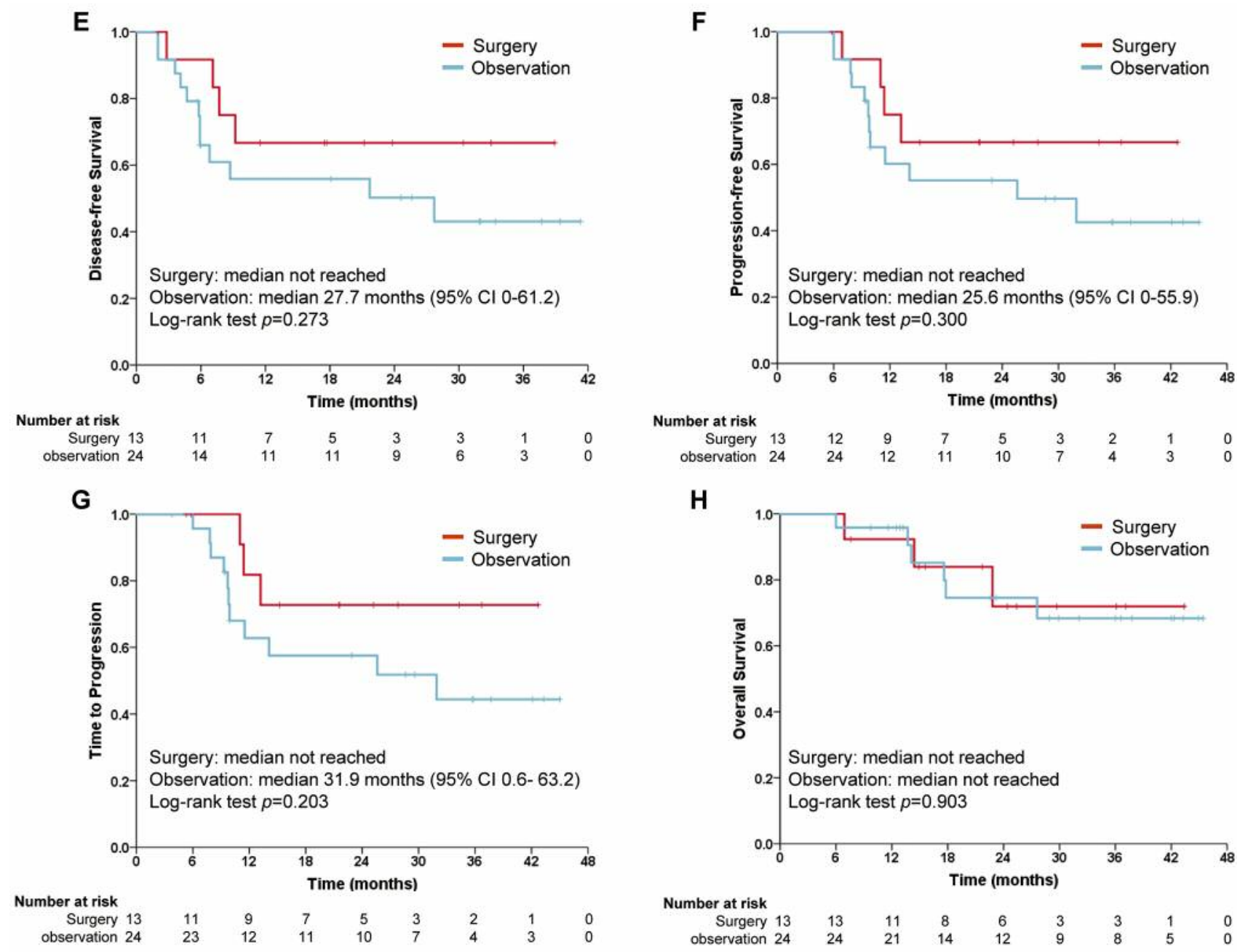

Figure 2. Disease-free survival, progression-free survival, time to progression, and overall survival according to treatment arm in the intent-to-treat analysis $(a-d)$ and in the as-treated analysis $(e-h)$ for the randomized patients.

$23.1 \%$ in the as-treated analysis $(p=0.288)]$, but most recurrences in the observation arm were resectable locoregional recurrences. Therefore, most patients $(72.7 \%)$ who had recurrence during observation could undergo salvage surgery or curative endoscopic dissection. This might have contributed to the lack of difference in survival between the two arms. In addition, a higher surgery-related mortality rate in the surgery arm $(5.3 \%$ vs. $0 \%$ in the intent-to-treat analysis; $7.7 \%$ vs. $0 \%$ in the as-treated analysis) might have negatively impacted survival in the surgery arm. Further research is needed in order to understand how minimally invasive esophagectomy affects the risk benefit ratio for surgery $v s$. surveillance in this setting (14).

Our results are consistent with those of previous studies comparing chemoradiation with or without surgery in EC. In a randomized phase III study by Stahl et al. (8), 172 patients with thoracic ESCC (cT3-4/N0-1/M0) were randomized to induction chemotherapy followed by chemoradiotherapy (40 Gy) and surgery or the same induction chemotherapy followed by chemoradiotherapy alone ( $\geq 65$ Gy). Chemoradiotherapy alone resulted in an equivalent OS to chemoradiotherapy plus surgery (14.9 vs. 16.4 month; $p=0.007$ for equivalence test) with less treatment-related mortality $(3.5 \%$ vs. $12.8 \% ; p=0.03)$. In a larger randomized phase III study (FFCD 9102), 259 patients with thoracic EC (mostly squamous cell carcinoma) (cT3/N0-1/M0) were randomized to continued chemoradiation or surgery once they achieved a clinical response to induction chemoradiation (9). Chemoradiation alone was equivalent to chemoradiation plus surgery in terms of OS (19.3vs. 17.7 months; $p=0.49)$ with a low 3 -month mortality rate $(0.8 \%$ vs. $9.3 \% ; p=0.002)$ and shorter hospital stay (52 vs. 68 days; $p=0.02$ ). 
A

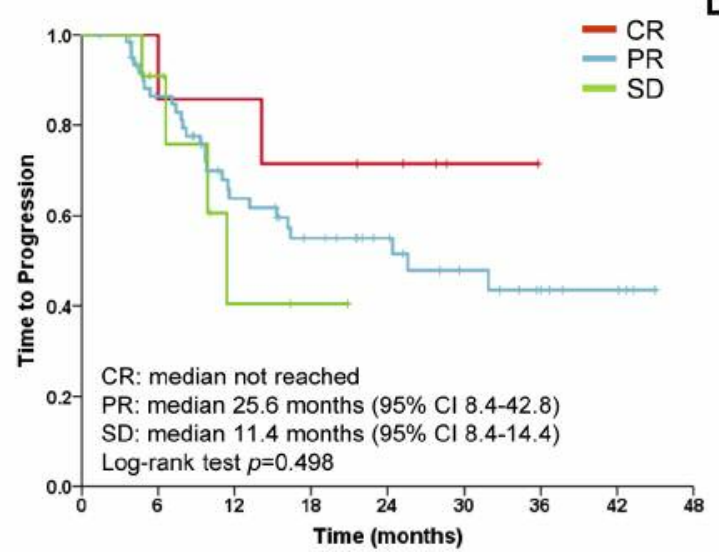

D

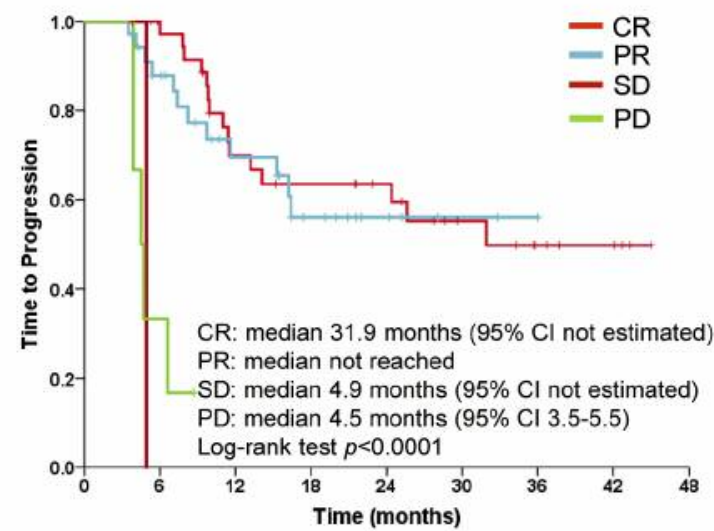

Number at risk

\begin{tabular}{|c|c|c|c|c|c|c|c|}
\hline CR 7 & 6 & 6 & 5 & 4 & 1 & 0 & 0 \\
\hline PR 62 & 49 & 31 & 23 & 17 & 11 & 6 & 4 \\
\hline D 12 & 8 & 2 & 1 & 0 & 0 & 0 & 0 \\
\hline
\end{tabular}

B

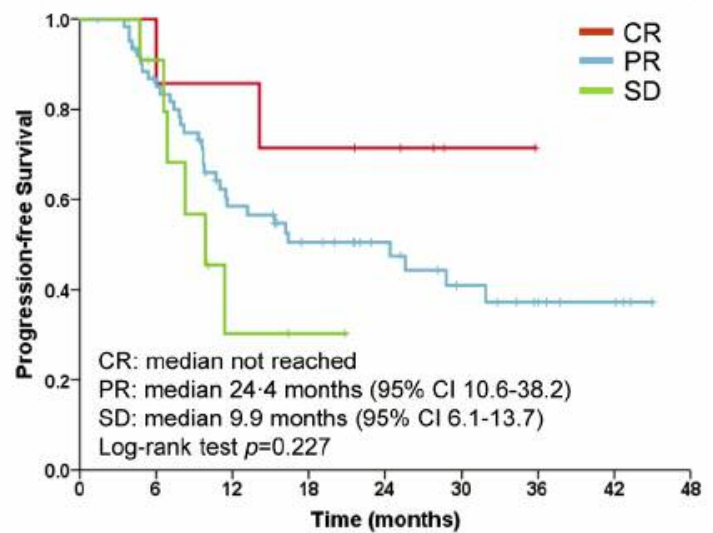

Number at risk

\begin{tabular}{|c|c|c|c|c|c|c|c|}
\hline CR 38 & 34 & 22 & 19 & 16 & 10 & 6 & 4 \\
\hline PR 35 & 27 & 17 & 10 & 5 & 2 & 0 & 0 \\
\hline SD 1 & 0 & 0 & 0 & 0 & 0 & 0 & 0 \\
\hline PD 6 & 2 & 0 & 0 & 0 & 0 & 0 & 0 \\
\hline
\end{tabular}

E

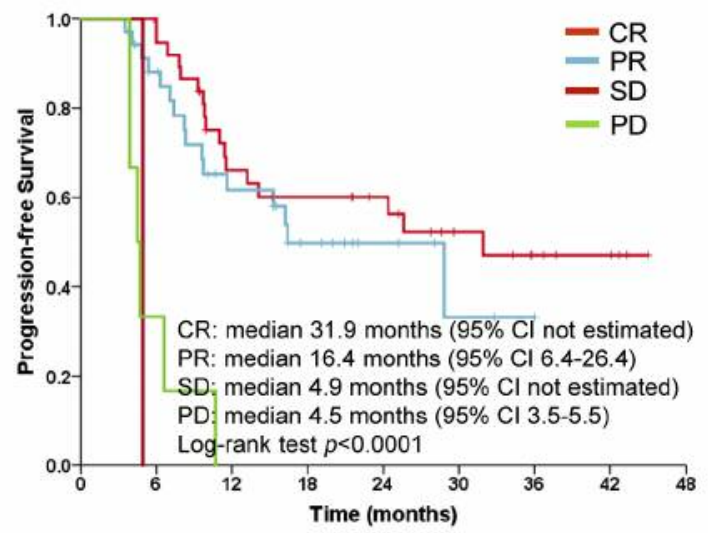

Number at risk

\begin{tabular}{|c|c|c|c|c|c|c|c|c|}
\hline CR 7 & 6 & 6 & 5 & 4 & 1 & 0 & 0 & 0 \\
\hline PR 62 & 50 & 31 & 23 & 17 & 11 & 6 & 4 & 0 \\
\hline SD 12 & 9 & 2 & 1 & 0 & 0 & 0 & 0 & . \\
\hline
\end{tabular}

Number at risk

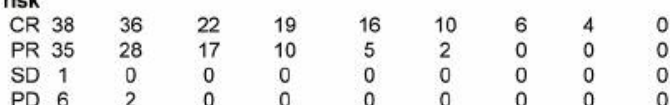

C

F

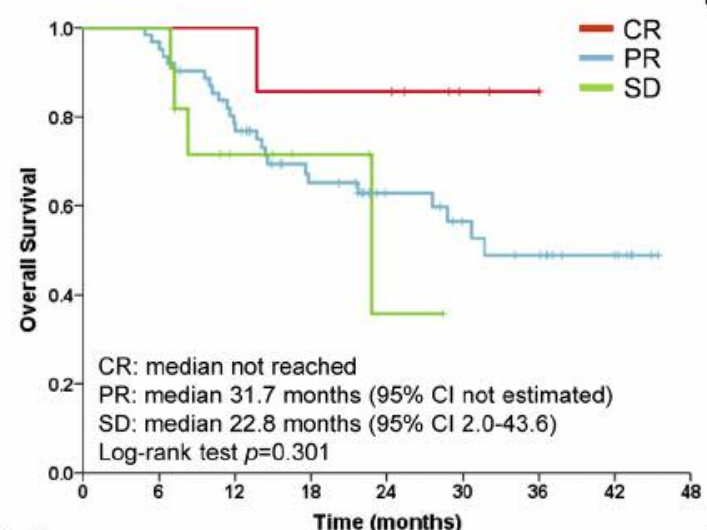

$F$

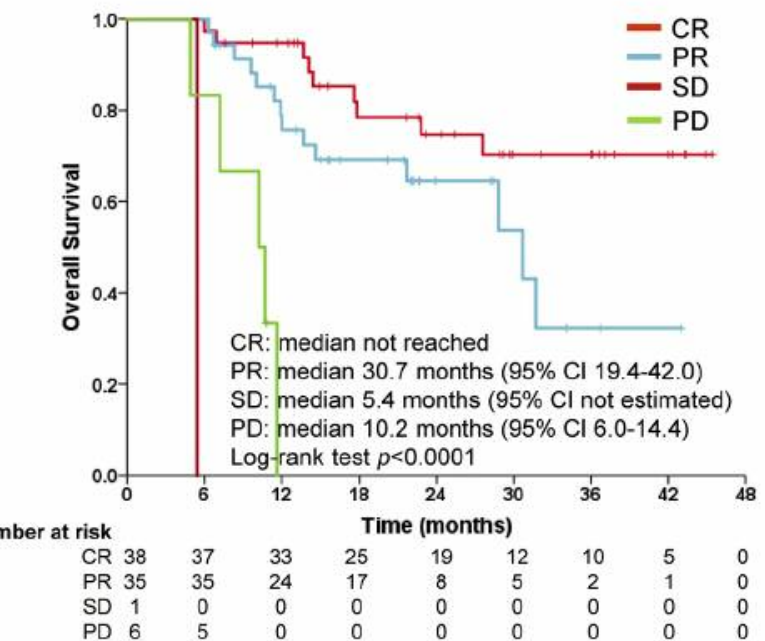

Figure 3. Time to progression, progression-free survival, and overall survival according to the metabolic response after induction chemotherapy (a-c) and chemoradiotherapy $(d-f)$ in all eligible patients. CR: Complete response; PR: partial response; SD: stable disease; PD: progressive disease. 


\begin{tabular}{|c|c|c|c|c|c|c|c|}
\hline & \multicolumn{4}{|c|}{ Intent-to-treat analysis } & \multicolumn{3}{|c|}{ As-treated analysis } \\
\hline & $\begin{array}{l}\text { Entire population } \\
\qquad(\mathrm{n}=82)\end{array}$ & $\begin{array}{c}\text { Surgery } \\
(\mathrm{n}=19)\end{array}$ & $\begin{array}{l}\text { Observation } \\
\quad(n=18)\end{array}$ & $p$-Value & $\begin{array}{l}\text { Surgery } \\
(\mathrm{n}=13)\end{array}$ & $\begin{array}{l}\text { Observation } \\
\quad(\mathrm{n}=24)\end{array}$ & $p$-Value \\
\hline Alive & $52(63.4 \%)$ & $15(78.9 \%)$ & $13(72.2 \%)$ & 0.736 & $10(76.9 \%)$ & $18(75.0 \%)$ & 0.465 \\
\hline Without recurrence or disease progression & $41(50.0 \%)$ & $12(63.2 \%)$ & $9(50.0 \%)$ & & $9(69.2 \%)$ & $12(50.0 \%)$ & \\
\hline With recurrence & $11(13.4 \%)$ & $3(15.8 \%)$ & $4(22.2 \%)$ & & $1(7.7 \%)$ & $6(25.0 \%)$ & \\
\hline Deaths & $30(36.6 \%)$ & $4(21.1 \%)$ & $5(27.8 \%)$ & 0.762 & $3(23.1 \%)$ & $6(25.0 \%)$ & 0.744 \\
\hline Cancer-related & $19(23.2 \%)$ & $3(15.8 \%)$ & $4(22.2 \%)$ & & $2(15.4 \%)$ & $5(20.8 \%)$ & \\
\hline Surgery-related & $6(7.3 \%)$ & $1(5.3 \%)$ & $0(0 \%)$ & & $1(7.7 \%)$ & $0(0 \%)$ & \\
\hline Other cause & $2(2.4 \%)$ & $0(0 \%)$ & $1(5.6 \%)$ & & $0(0 \%)$ & $1(4.2 \%)$ & \\
\hline Unknown & $3(3.7 \%)$ & $0(0 \%)$ & $0(0 \%)$ & & $0(0 \%)$ & $0(0 \%)$ & \\
\hline First failure pattern & & & & 0.056 & & & 0.067 \\
\hline Locoregional relapse & $13(15.9 \%)$ & $3(15.8 \%)$ & $8(44.4 \%)$ & & $1(7.7 \%)$ & $10(41.7 \%)$ & \\
\hline Distant metastasis & $4(4.9 \%)$ & $0(0 \%)$ & $0(0 \%)$ & & $0(0 \%)$ & $0(0 \%)$ & \\
\hline Locoregional relapse + distant metastasis & $3(3.7 \%)$ & $3(15.8 \%)$ & $0(0 \%)$ & & $2(15.4 \%)$ & $1(4.2 \%)$ & \\
\hline
\end{tabular}

Data are numbers $(\%)$.

The role of surgery is more controversial in patients achieving a cCR after chemoradiotherapy because they have favorable survival regardless of whether they undergo surgery (15-17). This issue will bring forth more attention when increased cCR is achieved with incorporation of immune checkpoint inhibitors in the neoadjuvant setting (18, 19). A retrospective study by Castoro et al. (15) showed that there were no significant differences in 5-year OS $(50.0 \%$ vs. $57.0 \% ; p=0.99)$ and 5 -year DFS (55.5\% vs. $34.6 \% ; p=0.15)$ between chemoradiotherapy plus surgery and chemoradiotherapy alone in thoracic ESCC patients obtaining a cCR after chemoradiation. Although the recurrence rate was numerically higher in chemoradiotherapy alone than in chemoradiotherapy plus surgery $(58 \% \mathrm{vs} .44 \%$; $p=0.25), 36.6 \%$ patients in the chemoradiation alone group had R0 salvage surgery at recurrence. A recent meta-analysis also showed that the addition of surgery to thoracic locally advanced EC patients with a cCR after neoadjuvant chemoradiotherapy provided no advantage to long-term survival $(\mathrm{HR}=1.361,95 \% \mathrm{CI}=0.572-3.239 ; p=0.486)$, while 2-year DFS could be improved (HR=3.186, 95\%CI=2.071$4.901 ; p=0.000)(20)$. These results along with ours suggest that watchful waiting then salvage surgery at recurrence could be a treatment option in the setting of $\mathrm{cCR}$ after chemoradiation. However, considering that patients in our study who underwent delayed salvage surgery were less likely to receive R0 resection and had significantly higher pathologic stages than patients who underwent immediate surgery after chemoradiation, close monitoring for early detection of recurrence may be needed during the observation period. Given that the median time to recurrence after randomization was 5.9 months $(95 \% \mathrm{CI}=4.6-7.2)$ in patients who had recurrence during observation under a follow-up schedule involving endoscopy and CT scans every 6 months, more frequent, short-term follow-up strategies need to be considered, particularly in the early observation period after cCR achievement.

On the other hand, because surgery after chemoradiation was associated with less local recurrence, less dysphagia before death ( $46 \%$ vs. 63\%; $p=0.04)$, and less requirement for procedures for dysphagia $(24 \%$ vs. $46 \% ; p<0.001)$ compared with chemoradiation alone in the FFCD 9102 study (9), there may be a role for surgery even in patients responding to chemoradiation. Furthermore, a retrospective case-control study suggested the survival benefits of surgery in patients who had a cCR after chemoradiation and were fit for surgery compared with surveillance (5-year OS, 58.9\% vs. 33.4\%; $p=0.001$ ) (21). In contrast to our study, this study included adenocarcinoma (15.9\%) as well as squamous cell carcinoma $(84.1 \%)$ and did not always use PET to assess cCR. To further optimize the treatment decision for individual patients, predictive factors for treatment efficacy and toxicity profiling need to be identified and efficacy and toxicity should be balanced for the two treatment strategies. In particular, a more accurate clinical assessment tool for predicting $\mathrm{pCR}$ and long-term survival after chemoradiation would help in the therapeutic decision making. A recent systemic review and meta-analysis suggested insufficient accuracy of endoscopic biopsies, endoscopic ultrasonography, and ${ }^{18}$ FDG-PET(-CT) as single modalities for detecting residual disease after neoadjuvant chemoradiotherapy for EC; pooled sensitivities and specificities were $33 \%$ and $95 \%$ for endoscopic biopsies, $96 \%$ and $8 \%$ for qualitative endoscopic ultrasonography, $74 \%$ and $52 \%$ for qualitative PET, $69 \%$ and $72 \%$ for PETSUVmax, and $73 \%$ and $63 \%$ for PET- $\% \Delta$ SUVmax (22). In 
our study using the combination of endoscopy with biopsy, chest CT, and PET-CT, the sensitivity, specificity, and accuracy of residual disease detection was $82.8 \%, 53.3 \%$, and $72.7 \%$, respectively, and a miss rate of residual disease was $39 \%$ (5 of 13). A Dutch prospective cohort study (preSANO) suggested that the miss rate for residual disease ( $>10 \%$ residual carcinoma in the resection specimen) using endoscopy with regular biopsy and fine-needle aspiration of suspicious LNs decreased from $31 \%$ to $10 \%$ after introduction of bite-on-bite biopsies, and the negative predictive value increased from $35 \%$ to $45 \%$ (23). For any residual disease ( $>0 \%$ residual carcinoma), however, this diagnostic strategy still had a high miss rate of $55 \%$ (23). The ongoing, randomized, phase III SANO trial has incorporated this diagnostic strategy and is comparing active surveillance with standard surgery in patients who achieve cCR after neoadjuvant chemoradiotherapy (24). Novel biomarkers such as circulating tumor DNA are an intriguing research area in predicting $\mathrm{pCR}$ and monitoring disease recurrence in the post-chemoradiation period.

A limitation of our study is the small sample size and because of that, this study is underpowered for drawing conclusions. Although we designed a high-volume singleinstitutional trial to avoid inevitable differences in surgical techniques among surgeons from a multi-institutional trial, a high rate of non-adherence to treatment assignment in the surgery arm led to early study closure. This high rate of drop-out for assigned treatment was attributed to 1) timing of randomization which was performed after obtaining cCR with chemoradiation while patient consent was obtained before initiating study treatment, and 2) change in treatment patterns in South Korea where nonsurgical approach in locally advanced esophageal cancer is more often used than before. Another limitation includes that quality of life data were not available due to a low response rate.

In conclusion, our study suggests that close observation with salvage surgery as appropriate might be a reasonable option in patients with thoracic ESCC achieving a cCR to chemoradiation. Further large-scale prospective studies are necessary to confirm our results and optimize the treatment decision in individual patients.

\section{Conflicts of Interest}

The Authors declare no conflict of interest relevant to this article.

\section{Authors' Contributions}

DHY, JHK, YHK, HYK, and SBK contributed to study design. SRP, DHY, JHK, YHK, HRK, HJL, HYJ, GHL, HJS, DHK, KDC, JHL, JYA, JSR, KJC, and SBK contributed to data collection. SRP, DHY, and SBK contributed to data analysis and interpretation. All Authors read and approved the final manuscript.

\section{Acknowledgements}

Funding: This research did not receive any specific grant from funding agencies in the public, commercial, or not-for-profit sectors.

\section{References}

1 Torre LA, Bray F, Siegel RL, Ferlay J, Lortet-Tieulent J and Jemal A: Global cancer statistics, 2012. CA Cancer J Clin 65(2): 87-108, 2015. PMID: 25651787. DOI: 10.3322/caac.21262

2 Kelsen DP, Ginsberg R, Pajak TF, Sheahan DG, Gunderson L, Mortimer J, Estes N, Haller DG, Ajani J, Kocha W, Minsky BD and Roth JA: Chemotherapy followed by surgery compared with surgery alone for localized esophageal cancer. N Engl J Med 339(27): 1979-1984, 1998. PMID: 9869669. DOI: 10.1056/ NEJM199812313392704

3 Bosset JF, Gignoux M, Triboulet JP, Tiret E, Mantion G, Elias D, Lozach P, Ollier JC, Pavy JJ, Mercier M and Sahmoud T: Chemoradiotherapy followed by surgery compared with surgery alone in squamous-cell cancer of the esophagus. N Engl J Med 337(3): 161-167, 1997. PMID: 9219702. DOI: 10.1056/NEJM 199707173370304

4 Walsh TN, Noonan N, Hollywood D, Kelly A, Keeling N and Hennessy TP: A comparison of multimodal therapy and surgery for esophageal adenocarcinoma. N Engl J Med 335(7): 462-467, 1996. PMID: 8672151. DOI: 10.1056/NEJM199608153350702

5 van Hagen P, Hulshof MC, van Lanschot JJ, Steyerberg EW, van Berge Henegouwen MI, Wijnhoven BP, Richel DJ, Nieuwenhuijzen GA, Hospers GA, Bonenkamp JJ, Cuesta MA, Blaisse RJ, Busch OR, ten Kate FJ, Creemers GJ, Punt CJ, Plukker JT, Verheul HM, Spillenaar Bilgen EJ, van Dekken H, van der Sangen MJ, Rozema T, Biermann K, Beukema JC, Piet AH, van Rij CM, Reinders JG, Tilanus HW, van der Gaast A and CROSS Group: Preoperative chemoradiotherapy for esophageal or junctional cancer. N Engl J Med 366(22): 2074-2084, 2012. PMID: 22646630. DOI: 10.1056/NEJMoa1112088

6 Tepper J, Krasna MJ, Niedzwiecki D, Hollis D, Reed CE, Goldberg R, Kiel K, Willett C, Sugarbaker D and Mayer R: Phase III trial of trimodality therapy with cisplatin, fluorouracil, radiotherapy, and surgery compared with surgery alone for esophageal cancer: CALGB 9781. J Clin Oncol 26(7): 10861092, 2008. PMID: 18309943. DOI: 10.1200/JCO.2007.12.9593

7 Sjoquist KM, Burmeister BH, Smithers BM, Zalcberg JR, Simes RJ, Barbour A, Gebski V and Australasian Gastro-Intestinal Trials Group: Survival after neoadjuvant chemotherapy or chemoradiotherapy for resectable oesophageal carcinoma: An updated meta-analysis. Lancet Oncol 12(7): 681-692, 2011. PMID: 21684205. DOI: 10.1016/S1470-2045(11)70142-5

8 Stahl M, Stuschke M, Lehmann N, Meyer HJ, Walz MK, Seeber S, Klump B, Budach W, Teichmann R, Schmitt M, Schmitt G, Franke $\mathrm{C}$ and Wilke $\mathrm{H}$ : Chemoradiation with and without surgery in patients with locally advanced squamous cell carcinoma of the esophagus. J Clin Oncol 23(10): 2310-2317, 2005. PMID: 15800321. DOI: 10.1200/JCO.2005.00.034

9 Bedenne L, Michel P, Bouche O, Milan C, Mariette C, Conroy T, Pezet D, Roullet B, Seitz JF, Herr JP, Paillot B, Arveux P, Bonnetain $\mathrm{F}$ and Binquet $\mathrm{C}$ : Chemoradiation followed by surgery compared with chemoradiation alone in squamous cancer of the esophagus: FFCD 9102. J Clin Oncol 25(10): 1160-1168, 2007. PMID: 17401004. DOI: 10.1200/JCO. 2005.04.7118 
10 Best LM, Mughal M and Gurusamy KS: Non-surgical versus surgical treatment for oesophageal cancer. Cochrane Database Syst Rev 3: CD011498, 2016. PMID: 27021481. DOI: 10.1002/ 14651858.CD011498.pub2

11 Young H, Baum R, Cremerius U, Herholz K, Hoekstra O, Lammertsma AA, Pruim J and Price P: Measurement of clinical and subclinical tumour response using $\left[{ }^{18} \mathrm{~F}\right]$-fluorodeoxyglucose and positron emission tomography: Review and 1999 EORTC recommendations. European Organization for Research and Treatment of Cancer (EORTC) PET Study Group. Eur J Cancer 35(13): 1773-1782, 1999. PMID: 10673991. DOI: 10.1016/ s0959-8049(99)00229-4

12 Eisenhauer EA, Therasse P, Bogaerts J, Schwartz LH, Sargent D, Ford R, Dancey J, Arbuck S, Gwyther S, Mooney M, Rubinstein L, Shankar L, Dodd L, Kaplan R, Lacombe D and Verweij J: New response evaluation criteria in solid tumours: Revised RECIST guideline (version 1.1). Eur J Cancer 45(2): 228-247, 2009. PMID: 19097774. DOI: 10.1016/j.ejca. 2008.10.026

13 van Meerten E, van der Gaast A, Tilanus HW, Poley JW, Muller $\mathrm{K}$ and van Dekken H: Pathological analysis after neoadjuvant chemoradiotherapy for esophageal carcinoma: The Rotterdam experience. J Surg Oncol 100(1): 32-37, 2009. PMID: 19402081. DOI: $10.1002 /$ jso.21295

14 van der Sluis PC, van der Horst S, May AM, Schippers C, Brosens LAA, Joore HCA, Kroese CC, Haj Mohammad N, Mook S, Vleggaar FP, Borel Rinkes IHM, Ruurda JP and van Hillegersberg R: Robot-assisted minimally invasive thoracolaparoscopic esophagectomy versus open transthoracic esophagectomy for resectable esophageal cancer: A randomized controlled trial. Ann Surg 269(4): 621-630, 2019. PMID: 30308612. DOI: $10.1097 /$ SLA.0000000000003031

15 Castoro C, Scarpa M, Cagol M, Alfieri R, Ruol A, Cavallin F, Michieletto S, Zanchettin G, Chiarion-Sileni V, Corti L and Ancona E: Complete clinical response after neoadjuvant chemoradiotherapy for squamous cell cancer of the thoracic oesophagus: Is surgery always necessary? J Gastrointest Surg 17(8): 1375-1381, 2013. PMID: 23797888. DOI: 10.1007/ s11605-013-2269-3

16 Adenis A, Tresch E, Dewas S, Romano O, Messager M, Amela E, Clisant S, Kramar A, Mariette C and Mirabel X: Clinical complete responders to definite chemoradiation or radiation therapy for oesophageal cancer: Predictors of outcome. BMC Cancer 13: 413, 2013. PMID: 3844443. DOI: 10.1186/14712407-13-413

17 Ishihara R, Yamamoto S, Iishi H, Takeuchi Y, Sugimoto N, Higashino $\mathrm{K}$, Uedo $\mathrm{N}$, Tatsuta $\mathrm{M}$, Yano $\mathrm{M}$, Imai $\mathrm{A}$ and Nishiyama K: Factors predictive of tumor recurrence and survival after initial complete response of esophageal squamous cell carcinoma to definitive chemoradiotherapy. Int J Radiat Oncol Biol Phys 76(1): 123-129, 2010. PMID: 19386426. DOI: 10.1016/j.ijrobp.2009.01.038

18 Hong M, Kim H, Park S, Kim D, Lee C, Cho J, Kim J, Kim H, Kim Y, Park S and Cho B: A phase II trial of preoperative chemoradiotherapy and pembrolizumab for locally advanced esophageal squamous cell carcinoma (ESCC). J Clin Oncol 37(suppl): abstr. 4027, 2019. DOI: 10.1200/JCO.2019. 37.15_ suppl.4027
19 van den Ende T, de Clercq NC, van Berge Henegouwen MI, Gisbertz SS, Meijer SL, Schokker S, Bergman JJGHM, Mohammad NH, Ruurda JP, van Hillegersberg R, Mook S, Nieuwdorp M, Soeratram TTD, Ylstra B, van Grieken NCT, de Gruijl TD, Bijlsma MF, Hulshof MCCM and Van Laarhoven HWM: A phase II feasibility trial of neoadjuvant chemoradiotherapy combined with atezolizumab for resectable esophageal adenocarcinoma: The PERFECT trial. J Clin Oncol 37(suppl): abstr. 4045, 2019. DOI: 10.1200/JCO.2019.37.15_suppl.4045

20 Wang J, Qin J, Jing S, Liu Q, Cheng Y, Wang Y and Cao F: Clinical complete response after chemoradiotherapy for carcinoma of thoracic esophagus: Is esophagectomy always necessary? A systematic review and meta-analysis. Thorac Cancer 9(12): 16381647, 2018. PMID: 30277016. DOI: 10.1111/1759-7714.12874

21 Piessen G, Messager M, Mirabel X, Briez N, Robb WB, Adenis $A$ and Mariette C: Is there a role for surgery for patients with a complete clinical response after chemoradiation for esophageal cancer? An intention-to-treat case-control study. Ann Surg 258(5): 793-799; discussion 799-800, 2013. PMID: 24096755. DOI: $10.1097 /$ SLA.0000000000000228

22 Eyck BM, Onstenk BD, Noordman BJ, Nieboer D, Spaander MCW, Valkema R, Lagarde SM, Wijnhoven BPL and van Lanschot JJB: Accuracy of detecting residual disease after neoadjuvant chemoradiotherapy for esophageal cancer: A systematic review and meta-analysis. Ann Surg, 2019. PMID: 31188203. DOI: $10.1097 /$ SLA.0000000000003397

23 Noordman BJ, Spaander MCW, Valkema R, Wijnhoven BPL, van Berge Henegouwen MI, Shapiro J, Biermann K, van der Gaast A, van Hillegersberg R, Hulshof M, Krishnadath KK, Lagarde SM, Nieuwenhuijzen GAP, Oostenbrug LE, Siersema PD, Schoon EJ, Sosef MN, Steyerberg EW, van Lanschot JJB and SANO study group: Detection of residual disease after neoadjuvant chemoradiotherapy for oesophageal cancer (preSANO): A prospective multicentre, diagnostic cohort study. Lancet Oncol 19(7): 965-974, 2018. PMID: 29861116. DOI: 10.1016/S1470-2045(18)30201-8

24 Noordman BJ, Wijnhoven BPL, Lagarde SM, Boonstra JJ, Coene P, Dekker JWT, Doukas M, van der Gaast A, Heisterkamp J, Kouwenhoven EA, Nieuwenhuijzen GAP, Pierie JEN, Rosman C, van Sandick JW, van der Sangen MJC, Sosef MN, Spaander MCW, Valkema R, van der Zaag ES, Steyerberg EW, van Lanschot JJB and SANO-study group: Neoadjuvant chemoradiotherapy plus surgery versus active surveillance for oesophageal cancer: A stepped-wedge cluster randomised trial. BMC Cancer 18(1): 142, 2018. PMID: 29409469. DOI: 10.1186/ s12885-018-4034-1

Received June 30, 2019

Revised July 29, 2019 Accepted August 1, 2019 